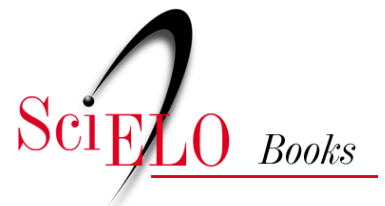

\title{
EDUFU
}

\section{Janusz Korczak e os direitos da criança entrelaçando vida e obra}

\author{
Ana Carolina Rodrigues Marangon
}

\section{SciELO Books / SciELO Livros / SciELO Libros}

MARANGON, A.C.R. Janusz Korczak e os direitos da criança: entrelaçando vida e obra. In: BOTO, C., ed. Clássicos do pensamento pedagógico: olhares entrecruzados [online]. Uberlândia: EDUFU, 2019, pp. 171-187. História, Pensamento, Educação collection. Novas Investigações series, vol. 9. ISBN: 978-65-5824-027-3. Available from: http://books.scielo.org/id/fjnhs/pdf/boto-9786558240273-09.pdf. https://doi.org/10.14393/edufu-978-85-7078-472-8.

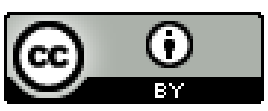

All the contents of this work, except where otherwise noted, is licensed under a Creative Commons Attribution 4.0 International license.

Todo o conteúdo deste trabalho, exceto quando houver ressalva, é publicado sob a licença Creative Commons Atribição 4.0.

Todo el contenido de esta obra, excepto donde se indique lo contrario, está bajo licencia de la licencia Creative Commons Reconocimento 4.0. 


\title{
Janusz Korczak e os direitos da criança: entrelaçando vida e obra
}

\author{
Ana Carolina Rodrigues Marangon
}

\section{Introdução}

Iniciou-se, em 1939, a Segunda Guerra Mundial. Os alemães invadiram a Polônia e tomaram a cidade de Varsóvia. Naqueles anos, pensamentos e sentimentos antissemitas já eram muito difundidos em alguns países da Europa; a Polônia era um deles. Por outro lado, a comunidade judia se organizava em torno do sionismo. Assim, a separação entre poloneses e judeus já era uma realidade.

Com o início da guerra, cresceu a ofensiva contra os judeus. Suas lojas foram fechadas, as casas pichadas, não havia mais trabalho e eles eram obrigados a se identificar pelo uso da estrela amarela.

Em 1940, criou-se o Gueto de Varsóvia, o destino dos judeus daquela região. Até esse momento, Janusz Korczak, médico e educador polonês, judeu, morava com 150 crianças num orfanato para crianças judias pobres, o qual havia idealizado e construído com ajuda da sociedade polonesa, na Rua Krochmalna - o, então, lado ariano da cidade.

Nesse orfanato, chamado Lar das Crianças, fundado em 1912, Korczak formou uma verdadeira República de Crianças. Nele, conseguiu observá-las, ouvi-las e conversar com elas. Tornou-se um 
especialista formado por verdadeiros especialistas em infância, as próprias crianças.

\section{Quem foi Janusz Korczak}

Janusz Korczak é o pseudônimo de Henryk Goldszmit. Filho e neto de médicos e advogados poloneses, Korczak nasceu em 22 de julho de 1878. Sua família, embora judia, era assimilada à cultura polonesa, e seus ascendentes, pertencentes à elite intelectual do país, lutavam pela aproximação entre judeus e poloneses. Todavia, de acordo com Lifton (1997), "O problema é revelado na semântica da questão: um Católico Polonês é chamado Polonês, mas um Judeu Polonês é chamado Judeu, não Polonês" (Lifton, 1997, p. 7)1. Muitos poloneses não consideravam um judeu, não importa quão esclarecido fosse, como um polonês.

Ainda menino, Korczak sentia a opressão contra o povo judeu e a força do sionismo; morando em um belo e luxuoso apartamento, era proibido de brincar com o filho do zelador e seus amigos. Eles, por sua vez, também não o queriam por perto. Por volta de 1942, enquanto esteve no Gueto de Varsóvia, Korczak escreveu sobre um episódio de sua infância: a morte de seu passarinho.

O canário era judeu.

E eu também.

Eu era judeu e ele polonês e católico. Ele estará um dia no paraíso; quanto a mim, com a condição de nunca pronunciar palavras feias e levar-lhe [ao filho do zelador] docilmente açúcar furtado em casa, poderei entrar após minha morte em alguma coisa que não é propriamente o inferno, mas onde, de toda forma, é muito escuro. $\mathrm{E}$ eu tive medo do escuro. A morte - judeu - o inferno. O escuro paraíso judeu. Dava o que pensar. (Korczak, 1986, p. 12-13).

\footnotetext{
${ }^{1}$ Tradução minha.
} 
De qualquer modo, Korczak teve uma infância feliz. Passava boa parte do tempo brincando em seu quarto ou ouvindo histórias que sua avó lhe contava. Aos 7 anos, passou a frequentar uma rígida escola russa, em que os castigos corporais eram frequentes e a língua e história polonesa, proibidas ${ }^{2}$.

Essa experiência proporcionou-lhe a certeza de que as crianças não eram respeitadas como os adultos. Foi justamente essa necessidade da busca pelo respeito às crianças que o levou a percorrer caminhos tão prósperos na maturidade.

$\mathrm{Na}$ adolescência, seu pai foi internado para tratamento e Korczak começou a tutorear o ensino de crianças para auxiliar nas despesas da casa. Em 1905, no mesmo ano em que ingressou na Faculdade de Medicina, seu pai faleceu.

Depois de formado, Korczak dividiu suas atividades entre o exercício da medicina no Hospital das Crianças e nos fronts russos da Guerra Russo-Japonesa e da Primeira Guerra Mundial. Além disso, viajou para alguns países para conhecer seus orfanatos e colônias de férias infantis. Entre essas atividades, conheceu Stefania Wilczinska, a grande amiga que o ajudou a idealizar e inaugurar o Lar das Crianças.

\section{O Lar das Crianças}

O Lar foi inaugurado em 1912, abrigando crianças entre 7 e 14 anos de idade. Essa casa possuía refeitórios, sala de estar, banheiros, biblioteca, dormitórios para as crianças e um para Korczak, o qual se situava ao lado do quarto dos meninos, bem como um para Stefania, situando-se este ao lado do quarto feminino.

O orfanato foi um dos primeiros em Varsóvia a possuir centrais de eletricidade e aquecimento. No primeiro piso, havia uma grande área clara e arejada que servia tanto como sala de jantar como para

\footnotetext{
${ }^{2}$ Nessa época, por volta de 1885 , a Polônia vivia sob o domínio do Império Russo. O czar havia proibido hinos e músicas populares polonesas, bem como o ensino da língua e da história do país nas escolas.
} 
estudo e área de brincadeiras. Os banheiros tinham vasos sanitários com descargas e pias de porcelana com água quente e fria. Tudo era limpo e bonito. Entre os dormitórios feminino e masculino havia uma pequena sala de vidros, de onde Korczak observava as crianças durante a noite.

Com muito diálogo entre as crianças, Korczak e Stefania conseguiram, ainda antes da Primeira Guerra, que o orfanato se organizasse mediante a autogestão. As próprias crianças seriam as responsáveis por atividades que envolviam toda a administração e convivência interior. A autonomia de pensamento e sentimentos, bem como aquela propiciada pela tomada de atitudes e suas responsabilidades propiciava a formação de cidadãos felizes, responsáveis e conscientes de seus atos.

Todavia, abrigar cerca de 150 crianças oriundas de famílias distintas e com idades diferentes exigia que mecanismos de organização e comunicação fossem desenvolvidos. Assim, com o passar do tempo, algumas invenções auxiliaram nesse sentido: o quadro de avisos, a caixa de cartas, a vitrina dos objetos achados, a divisão do trabalho, as reuniões-debate, o jornal, o Tribunal de Arbitragem, o Código do Tribunal de Arbitragem, os juízes e demais membros.

Por meio desses instrumentos, Korczak procurou estabelecer e aprofundar o vínculo entre as próprias crianças e delas com os educadores. $\mathrm{O}$ quadro de avisos e a caixa de cartas possibilitavam a agilidade na comunicação e no atendimento das necessidades individuais dos internos. A criação da vitrina dos objetos achados ressalta a sensibilidade e o respeito de Korczak pelo universo infantil. Nela eram guardados todos os objetos achados no orfanato, desde um cartão de lembrança até uma pedra "de estimação". Para Korczak, era necessário respeitar os valores e sentimentos que as crianças depositavam em seus pertences, mesmo que, aos olhos adultos, não possuíssem valor algum.

Nas reuniões-debate, todos podiam falar, expor opiniões, discordar para que, enfim, se chegasse a um acordo. Com o tempo, as 
crianças perceberam que podiam dizer o que pensavam e reclamar do que achavam injusto, uma vez que não seriam punidas por isso. Seus pensamentos, dúvidas e sentimentos eram ouvidos e respeitados.

Os acontecimentos da vida no Lar eram revisitados semanalmente por meio da leitura de um jornal interno. Korczak se reunia com as crianças e lia o ocorrido naquela semana. Além das notícias semanais, todos podiam enviar poemas e mensagens para serem lidos no jornal. Desse modo, estabelecia-se o vínculo entre uma semana e outra da vida no Lar.

Todavia, o objetivo de oferecer à criança um tratamento imparcial, sério e de respeito concretizou-se com o Tribunal de Arbitragem. E Janusz Korczak justifica a atenção dada a ele:

O lugar que dedico neste livro aos tribunais das crianças pode parecer, para alguns, demasiadamente importante. É porque vejo neles o primeiro passo para a emancipação da criança, a elaboração e proclamação de uma Declaração dos Direitos da Criança. Ela tem direito de exigir que seus problemas sejam tratados com imparcialidade e seriedade. Até agora tudo dependia da boa ou má vontade do educador, do seu humor naquele dia. Realmente é tempo de se pôr fim a esse despotismo. (Korczak, 1997, p. 332).

Cabe relembrar que o orfanato foi inaugurado em 1912 e que a obra em que Korczak o apresenta, bem como seus ideais educacionais, foi escrita no front da Primeira Guerra Mundial, sendo originalmente publicada em 1920. Portanto, em 1914, tudo o que é aqui descrito já era uma realidade concreta naquela República de Crianças.

O Tribunal de Arbitragem é apenas uma das muitas tentativas de se modificar a maneira de julgar os iguais. Os adultos possuem seus tribunais. Nas escolas, os juízes são os professores. No Lar das Crianças, optou-se por um tribunal composto e organizado pelas próprias crianças. Esse tribunal era o responsável pela inocência ou a culpabilidade de quem fosse citado nele. 
Para se queixar ao Tribunal de Arbitragem, a criança escrevia em um quadro o assunto da sua queixa, seu nome, bem como o daquele a quem citava na justiça. Todos, crianças e adultos, podiam ser citados no Tribunal. O próprio Korczak foi julgado cinco vezes ${ }^{3}$. O Tribunal de Arbitragem possuía seu próprio código, o Código do Tribunal de Arbitragem, que começava sempre por perdoar o culpado.

Se alguma criança agiu mal, começamos por perdoá-la. Porque se o fez por ignorância, de agora em diante, poderá agir com conhecimento de causa; se fez involuntariamente, procurará, no futuro, ser mais prudente; se o fez porque não consegue se livrar dos maus hábitos, esperemos que da próxima vez consiga isso; se o fez por instigação de um companheiro, quem sabe, na próxima vez, não queira mais ouvir esse amigo. (Korczak, 1997, p. 332).

Como se viu, o Tribunal começava por perdoar a criança citada. Todavia, se mesmo mediante o primeiro perdão a criança se recusasse a melhorar, seu caso era encaminhado para estudo ao Conselho Jurídico do Tribunal. De qualquer modo, o Tribunal zelava pelo respeito à pessoa humana.

O tribunal vigia para que o grande não maltrate o pequeno, e que este não importune o grande, que um esperto não explore um de boa-fé, e que um engraçadinho não faça brincadeiras com um que não goste de bancar o palhaço; que um menino de mau gênio não procure brigas e discussões, mas que também os outros tratem de não provocá-lo à toa. $\mathrm{O}$ tribunal deve vigiar para que todas as crianças disponham do

3 "Fui julgado cinco vezes. A primeira vez porque puxei as orelhas de um menino; a segunda pus para fora do dormitório um menino barulhento; a terceira, porque mandei um outro ficar de castigo no canto; a quarta, porque insultei um juiz; a quinta porque suspeitei que uma menina tivesse roubado. Nos três primeiros processos, fui julgado por causa do Artigo 21; no quarto processo, foi o Artigo 71; e no último, foi usado o Artigo 7. Para cada processo escrevi uma longa deposição". (Korczak, 1997, p. 380). 
que precisam e que não tenham razão para ficar tristes ou enraivecidas (Korczak, 1997, p. 335).

Porém, em um orfanato com mais de uma centena de internos, havia crianças que possuíam dificuldades de seguir o regulamento, mesmo quando feito por elas mesmas. Por esse motivo, existiam os "casos especiais" e o Conselho Jurídico tinha o direito de declarar qualquer caso como "caso especial", até que o próprio interessado decidisse que ele não deveria mais ser considerado assim. Cabia ao Conselho, também, a decisão de afixar a lista com os seus nomes no quadro do Tribunal.

O Código do Tribunal de Arbitragem possuía mil artigos ${ }^{4}$. De acordo com Korczak (1997), os primeiros 99 eram de absolvição ou improcedência. "Tudo se passa como se o delito nunca tivesse existido; para encorajar o acusado a não mais recomeçar, o julgamento relembrará algumas coisas de seus erros" (Korczak, 1997, p. 337-338). $\mathrm{O}$ artigo 100 indicava uma condenação leve e, por isso, o julgamento era inserido na curva de delitos. Os artigos seguintes apontavam a culpa e, seguindo uma ordem crescente de acusações e reincidências, no artigo 500, por exemplo, o culpado tinha seu nome publicado na primeira página do jornal do Tribunal. $\mathrm{O}$ artigo 600 apresentava como penalidade afixar o nome do acusado no quadro do Tribunal e aquele cuja sentença era o artigo 700 tinha sua condenação enviada à família. Já no artigo 800, o Tribunal se declarava impotente e recomendava uma semana de reflexão ao acusado. $\mathrm{O}$ artigo 900 declarava a falta de esperança na melhora e indicava o desejo do Tribunal de que o referido réu deixasse a instituição. Todavia, uma criança ou um educador ainda podera se responsabilizar por ele, oferecendo-se como seu tutor. Nesse caso, era o tutor quem respondia por suas faltas diante do Tribunal. $\mathrm{O}$ artigo 1.000 expulsava o culpado do Lar, mas este poderia pedir sua volta depois de três meses da expulsão.

\footnotetext{
${ }^{4}$ Janusz Korczak descreveu parte desses artigos em seu livro "Como amar uma criança”.
} 
Em seu livro Como amar uma criança (1997), Korczak explica a curva das sentenças, cuja responsabilidade era do Conselho Jurídico. "Assim, se o tribunal fez quatro julgamentos segundo o Artigo $100(100 \times 4=400)$, seis segundo o Artigo $200(200 \times 6=1200)$ e um conforme o Artigo 400, o total será 400+1200+400=2000, nós notaremos que a curva das sentenças da semana subiu a 2000" (Korczak, 1997, p. 340). Pela curva, poder-se-ia conferir como caminhava a saúde moral do orfanato.

A existência do Tribunal no orfanato possibilitou o exercício real da democracia no Lar. Todavia, seu processo de construção e aceitação foi lento e tumultuado.

O tribunal não serve para nada porque as crianças não têm medo dele, porque não se importam com ele - ouvir isso era realmente penoso, e eu me perguntava se era válida a existência desta instituição... observei uma coisa interessante: se, no começo, os juízes tinham a tendência de não levar a sério as queixas dos meninos pequenos, mesmo aquelas referentes a surras, apelidos ofensivos etc... compreenderam logo que a gravidade de um caso deveria ser considerada conforme o sofrimento da vítima, o sentimento que tinha de ter sido injustiçada. (Korczak, 1997, p. 374).

O acompanhamento das atividades do Tribunal, a atenção às queixas das crianças, bem como às suas reações possibilitou que Korczak compreendesse profundamente o universo infantil. Atento, apreendeu sua dor, sua mágoa, seu ódio e sua felicidade durante a realização das sessões e a divulgação das sentenças.

Muitas vezes um processo me fazia conhecer melhor uma criança que vários meses de contato com ela. Como secretário do tribunal pude estudar as minúcias desse mundo à parte que é o mundo das crianças. Procurando me aperfeiçoar sempre, tornei-me um expert. (Korczak, 1997, p. 375). 
A regra fundamental de Janusz Korczak era a garantia do direito ao respeito devido à criança como pessoa para que ela pudesse ser o que era e viver o seu momento presente, sendo feliz nele.

Para mim, como sem dúvida, para todos os educadores, "as crianças" não existem, existem seres humanos, cada um dotado de uma personalidade própria, cada um reagindo de um modo tão diferente em relação ao mundo que o rodeia, que esta censura só pode provocar um sorriso indulgente. (Korczak, 1997, p. 379-380).

\section{Os direitos da criança}

A leitura atenta das obras de Janusz Korczak nos possibilita apreender suas considerações acerca da criança e sua compreensão do mundo infantil. Torna-se evidente o olhar observador do estudioso, que auxilia na identificação e no diagnóstico de problemas com as crianças. Essa observação, herdada da prática médica e transportada para a pedagógica, possibilitou que Korczak identificasse alterações no comportamento que indicavam o prenúncio de algum mal-estar físico, além de oportunizar-lhe o conhecimento da psique humana.

Quanto mais se aproximar da criança, mais verá nela coisas dignas de sua atenção. E é nessa observação escrupulosa que encontrará sua recompensa e a coragem para novos esforços, que permitam que vá sempre em frente. (Korczak, 1997, p. 252).

É essa dimensão de amor e respeito pela criança que parece evidente em seus escritos. Korczak não amava a criança como um ser puro e bondoso. Ao contrário, ele reconhecia sua maldade, seu desejo de vingança, sua tristeza, sua alegria, sua raiva, seu ódio, sua mágoa, enfim. A criança não era, para Korczak, sinônimo de pureza, bondade e honestidade. Ela era um ser humano como qualquer outro, tendo, por isso, desejos, vontades, sonhos, amores, ódios, mágoas, frustrações 
etc. Essa dimensão humana do amar a criança propunha, portanto, que ela fosse respeitada como um ser; o educador não deveria se sobrepor a ela por ser maior, mais forte ou mais velho, devendo sua ação ser limitada mediante o direito que a criança possuía de ser ouvida, de ter sua vontade e necessidades respeitadas e não massacradas pela simples satisfação adulta.

Faz-se interessante ressaltar que essa preocupação de Korczak com os direitos que as crianças possuem de ser consideradas e respeitadas como seres humanos o levou a escrever uma obra cujo título é $O$ direito da criança ao respeito. Nela, Korczak aponta suas reflexões referentes às situações que observou, salientando momentos de menosprezo, desconfiança e má vontade vividos pelas crianças. Ademais, discorre com primazia sobre o direito de a criança ter direitos, de ser compreendida como alguém no presente e não como um futuro homem.

Entretanto, respeitar o infante não significava autorizá-lo a fazer tudo o que desejasse. Os limites são necessários para a vida em sociedade e, por isso, para a boa educação da criança, é preciso que ela mesma reconheça e respeite os seus limites.

- Eu não quero.

Não quer ir dormir, apesar de já ter soado a hora de recolher, porque a noite está perfumada, ou porque um pedaço do céu estrelado parece estar brilhando para ela. Não quer ir à escola porque caiu a primeira neve durante a noite e lá fora está tão alegre que não quer se trancar numa sala de aula. Não quer se levantar porque está fazendo frio e tudo parece tão triste... Prefere acabar o jogo de bola e ficar sem almoçar. Não, eu não pedirei desculpas para a professora, porque ela me puniu injustamente... Não posso fazer meus deveres porque li Robinson Crusoe e estou com a cabeça cheia de aventuras... Não porei minhas calças curtas porque os outros vão rir de mim.

— Você deve! ...

— Estude! Respeite! Acredite no que lhe dizem!

— Eu não quero! - a criança se insurge do fundo da alma. 
Você se obriga a insistir porque o homem contemporâneo não vive na floresta, mas em sociedade.

E você deve insistir, caso contrário, será a anarquia. (Korczak, 1997, p. 199-200).

O respeito foi, certamente, o alicerce que sustentou toda a construção pedagógica de Korczak. Ele buscou compreender os medos, as angústias, as vontades infantis; tentou respeitar as crianças ao máximo.

Conforme José Augusto Dias (2002), a primeira ideia original de Korczak é de que a infância não é um período, mas um estado.

Nesse ponto ele se inscreve de imediato contra a corrente de psicologia qualificada de genética. [...] A criança, para a psicologia genética, não é certamente um adulto em miniatura, mas é um adulto em devir. Ora, Korczak reverteu o problema, ao dizer que atualmente um terço da humanidade é constituído de crianças e que, ao invés de considerálas como seres imaturos, seria mais normal e mais justo considerá-las como uma minoria oprimida. (Dias, 2002, p. 8).

De qualquer forma, Janusz Korczak e suas crianças judias viviam numa Polônia repleta de pensamentos sionistas e antissemitas. Essa realidade determinou os passos de suas vidas. Em 1939, a Polônia foi invadida pelos alemães, iniciando a Segunda Grande Guerra. Sob o comando nazista, o país se encontrou em estado caótico. A capital, Varsóvia, foi praticamente destruída. A política antissemita intensificava-se constantemente e as lojas e fábricas judias foram apropriadas ou estavam fechadas e destruídas. Era cada vez mais difícil conseguir remédios e comida. A Associação de Ajuda aos Órfãos sugeriu que Korczak entregasse suas crianças aos pais ${ }^{5}$ para que se

\footnotetext{
${ }^{5}$ A maioria das crianças que habitavam o orfanato eram filhos de pais muito pobres. Esses internos visitavam a família semanalmente. Os demais eram realmente órfãos.
} 
responsabilizassem por elas nesses dias difíceis, mas ele se recusou a fazer isso. Nessa época, o orfanato abrigava 150 crianças.

Em 1940, com a criação do Gueto de Varsóvia, Korczak não pôde mais manter o Lar no lado ariano da cidade.Assim, mudou-se para o Gueto com Stefania e todas as crianças. Lá, eles tentavam amenizar aquela bruta realidade aos olhos das crianças, por isso, organizavam representações teatrais, aulas de música e contação de histórias. Eles buscavam envolvê-las numa atmosfera de alegria, paz e segurança durante o maior espaço de tempo possível. Além disso, as atividades comuns do orfanato continuaram ocorrendo, como o jornal interno, as listas e o Tribunal. Korczak sairia de lá em 1942, acompanhado por 200 crianças rumo aos trens que levavam às câmaras de gás de Treblinka.

A mudança para o Gueto e a tentativa da manutenção da ordem e da paz para as crianças é apontada por estudiosos que se debruçaram sobre a obra de Janusz Korczak. Cabe ressaltar que essa mesma situação foi representada no filme Uprising, cujo título, traduzido para a língua portuguesa, é Insurreição (2001). O filme apresenta diálogos entre Korczak e Adam Czerniakow - presidente do Conselho Judaico da Polônia, um órgão criado pelos nazistas -, bem como, brevemente, o trabalho desenvolvido pelo primeiro no Gueto de Varsóvia, como as apresentações infantis de música e seu esforço para amenizar a animalidade do ambiente para as criançaEm 1942, inicia-se a transferência da massa humana dos campos de concentração para os campos de extermínio nazista. Em agosto, Korczak e as, então, 200 crianças foram encaminhados em vagões de trem ao Campo de Treblinka. A trajetória de Janusz Korczak e suas crianças ao trem que os levaria ao campo de extermínio foi muito descrita. Diz-se que ele caminhou à frente das crianças, que o seguiam em fila, carregando outras duas no colo, que não conseguiam mais andar. Essa cena também é apresentada no filme já citado. Nela, Korczak lidera uma grande fila de crianças magras, fracas e maltrapilhas. Um dos policiais judeus tenta impedi-lo de entrar no vagão e ele afirma que a única forma de fazer isso seria matá-lo ali 
mesmo, do lado de fora do trem, perto das crianças. Janusz Korczak acompanha os órfãos no vagão de gado.

A política nazista de Hitler negou ao homem o que Hannah Arendt (1987) classificou como a essência dos direitos humanos, que é justamente o direito de ter direitos.

Ao dar entrada num campo de concentração nazista, o prisioneiro não perdia apenas a liberdade e a comunicação com o mundo exterior. Não era, tão-só, despojado de todos os seus haveres: as roupas, os objetos pessoais, os cabelos, as próteses dentárias. Ele era, sobretudo, esvaziado do seu próprio ser, da sua personalidade, com a substituição altamente simbólica do nome por um número, freqüentemente gravado no corpo, como se fora a marca de propriedade de um gado. O prisioneiro já não se reconhecia como ser humano, dotado de razão e sentimentos: todas as suas energias concentravam-se na luta contra a fome, a dor a exaustão. (Comparato, 2001, p. 23).

Com o término da Segunda Guerra, constatando-se o número de vítimas - cerca de 60 milhões de pessoas mortas - e os abusos cometidos por alguns países contra os direitos humanos, sentiu-se a necessidade da criação de um órgão que fosse capaz de regular a vida social do mundo. Assim, foi criada a Organização das Nações Unidas (ONU). A ONU nasceu para organizar a sociedade política mundial do pós-guerra, buscando a defesa da dignidade humana e da soberania dos povos. Deveriam integrar a Organização das Nações Unidas todos os países do globo preocupados em defender a integridade de seu território e a segurança de seus cidadãos. Três anos após sua criação, em 1948, a ONU pôs a público a Declaração Universal dos Direitos Humanos, que, "retomando os ideais da Revolução Francesa, representou a manifestação histórica de que se formara, enfim, em âmbito universal, o reconhecimento dos valores supremos da igualdade, da liberdade e da fraternidade entre os homens" (Comparato, 2001, p. 226). Bobbio (1992) afirma que a 
Declaração representa um consenso geral acerca de um sistema de valores fundado pelo homem.

Somente depois da Declaração Universal é que podemos ter a certeza histórica de que a humanidade - toda a humanidade - partilha alguns valores comuns; e podemos, finalmente, crer na universalidade dos valores, no único sentido em que tal crença é historicamente legítima, ou seja, no sentido em que universal significa não algo dado objetivamente, mas algo subjetivamente acolhido pelo universo dos homens. (Bobbio, 1992, p. 28).

Assim, como parte do processo histórico, a comunidade internacional busca, além de garantir os direitos citados na Declaração, ampliá-los, aperfeiçoando-os continuamente - como afirmou Bobbio (1992) -, fazendo-os crescer a partir de si mesmos. Nesse processo de desenvolvimento progressivo dos Direitos Humanos, a Declaração de 1948 estabeleceu um alicerce geral sobre o qual os direitos específicos foram construídos. Como um exemplo, temos a Declaração dos Direitos da Criança, adotada pela Assembleia Geral da ONU em 20 de dezembro de 1959, que, em seu preâmbulo, "apresenta o problema dos direitos da criança como uma especificação da solução dada ao problema dos direitos do homem" (Bobbio, 1992, p. 35). Por esse motivo, o destaque da especificidade dos direitos infantis firmar-se-ia mediante a elaboração de um novo documento, calcado sobre as diretrizes expressas pela Declaração Universal dos Direitos Humanos de 1948.

A Declaração dos Direitos da Criança, inspirada também na Convenção de Genebra, de 1924, consubstancia princípios em relação à criança e ao adolescente pelos quais se devem pautar todos os países do globo. Seus dez princípios proclamam uma infância feliz, que desfrute de direitos e liberdades. Desse modo, direitos como igualdade, desenvolvimento pessoal global, cidadania, amor, compreensão, educação, lazer e proteção permeiam a construção de todo o documento. 
A criança gozará de proteção de todos os direitos enunciados nesta Declaração. Todas as crianças, absolutamente sem qualquer exceção, serão credoras destes direitos, sem distinção ou discriminação por motivo de raça, cor, sexo, língua, religião, opinião política ou de outra natureza, origem nacional ou social, riqueza, nascimento ou qualquer outra condição, quer sua ou de sua família [...] ser-lhe-ão proporcionadas oportunidades e facilidades, por lei ou por outros meios, a fim de lhe facultar o desenvolvimento físico, mental, moral, espiritual e social de forma sadia e normal e em condições de liberdade e dignidade [...] Desde o nascimento, toda criança terá direito a um nome e a uma nacionalidade [...] Para o desenvolvimento completo e harmonioso de sua personalidade, a criança precisa de amor e compreensão. Criar-se-á, sempre que possível, aos cuidados e responsabilidades dos pais e, em qualquer hipótese, num ambiente de afeto e de segurança moral e material [...] A criança terá direito a receber educação, que será gratuita e compulsória pelo menos no grau primário. Ser-lhe-á propiciada uma educação capaz de promover a sua cultura geral e capacitá-la a, em condições de iguais oportunidades, desenvolver as suas aptidões, sua capacidade de emitir juízo e seu senso de responsabilidade moral e social, e a tornar-se um membro útil na sociedade [...] A criança terá ampla oportunidade para brincar e divertir-se, visando aos propósitos mesmos da sua educação [...] A criança gozará de proteção contra quaisquer formas de negligência, crueldade e exploração (Miranda, 1999, p. 71-74).

A Declaração dos Direitos da Criança representa o marco inicial na luta jurídica pelos direitos infantis. Ela estabelece cláusulas que asseguram a igualdade entre as crianças - independentemente de cor, raça, religião, nacionalidade -, apontando para a necessidade de se criarem meios para o pleno desenvolvimento infantil. A educação é compreendida como responsável pela formação cultural geral, pelo desenvolvimento das aptidões (as habilidades e as competências), pela formação de cidadãos responsáveis e aptos para o convívio 
social. A Declaração de 1959 garante à criança, ainda, o direito ao amor e à compreensão, à diversão e a brincadeiras. Além disso, o direito de ser criada, sempre que possível, pelos pais, envolta por afeto e segurança moral.

Como se sabe, ideais de proteção, amor e respeito para com as crianças já haviam sido anteriormente propalados, muito particularmente na história recente. A vida e a obra de Janusz Korczak são mundialmente reconhecidas por sua exemplaridade e pelo ideal de propiciar às crianças de todo o mundo o direito a ter sua individualidade respeitada.

Por todo o seu trabalho e obra e, principalmente, pelo profundo respeito que demonstrava à criança, Janusz Korczak foi reconhecido como o pioneiro na luta pelos direitos da criança. Ele foi o precursor da Declaração dos Direitos da Criança, em virtude do fato de suas ideias servirem de inspiração para a Convenção de Genebra (1924).

Após o término da Segunda Guerra Mundial, muitos monumentos foram erguidos para homenagear aquele que foi reconhecido como um grande médico, educador e, principalmente, defensor das crianças.

$\mathrm{O}$ que me impressiona em Korczak é que encontro nele aquela simplicidade, compromisso e coerência que, acima de qualquer categoria lógica, definem um educador. Ele não precisou estruturar previamente nenhuma teoria abstrata para se dirigir à criança. Não se encontrava com elas com esquemas prontos para moldá-las segundo algum modelo. Ao contrário, ao resgatar-lhes primeiro a identidade, aprendia a ser gente com elas. Numa época de fascínio pelo positivismo científico e pela uniformização da educação, ele chamava a atenção para o respeito, o amor, a fala, o prazer, a autogestão pedagógica, a espontaneidade, que fazem o cotidiano da Educação. (Gadotti, 1996, p. 56).

Pelo exposto, é possível notar a importância da reflexão e do conhecimento que Janusz Korczak desenvolveu acerca da criança, do 
seu modo de viver, de interpretar o mundo, bem como do direito ao respeito por ser quem é.

Superar algumas fronteiras educacionais pode requerer o empréstimo de pensamentos como os de Janusz Korczak, que procurava enxergar seu mundo com olhos de criança e oferecer esse olhar a quem se dispusesse a ver.

\section{Referências}

ARENDT, Hannah. A condição humana. Rio de Janeiro: Forense, 1987.

BOBBIO, Norberto. A era dos direitos. Rio de Janeiro: Campus, 1992.

COMPARATO, Fábio Konder. A afirmação histórica dos direitos humanos. São Paulo: Saraiva, 2001.

DALLARI, D. de A., KORCZAK, J. O direito da criança ao respeito. São Paulo: Summus, 1986.

DIAS, José Augusto. Originalidade de Janusz Korczak. Boletim da Associação Janusz Korczak do Brasil, São Paulo, n. 6, 2002, p. 7-9.

GADOTTI, M. Korczak, precursor dos direitos da criança. In: IOKOI, Z. M. G.; BITTENCOURT, C. M. F. (Org.). Educação na América Latina. Rio de Janeiro: Expressão e Cultura; São Paulo: Edusp, 1996.

INSURREIÇÃO. Direção: Jon Avnet. Produção: Jon Avnet e Raffaella de Laurentis. Intérpretes: Lee Lee Sobieski, Hank Azaria, David Achimmer, Jon Voight, Donald Suthereand e outros. Roteiro: Paul Brickman e Jon Avnet. Música: Maurice Jarre. Brooklyn Films; Warner Home Video, 2001.

KORCZAK, Janusz. Diário do gueto. São Paulo: Perspectiva, 1986.

KORCZAK, Janusz. Como amar uma criança. Rio de Janeiro: Paz e Terra, 1997.

LIFTON, B. J. The king of children. Nova York: Martin's Griffin, 1997.

MARANGON, Ana Carolina Rodrigues. Janusz Korczak, precursor dos direitos da criança: uma vida entre obras. São Paulo: Editora Uunesp, 2007.

MIRANDA, Sandra Julien (Org.). Criança e adolescente: direito a diretos. São Paulo: Rideel, 1999. 